\title{
Effect of Coarse Aggregate Gradation and Water- Cement Ratio on Unit Weight and Compressive Strength of No-fines Concrete
}

\author{
Zaheer Ahmed Tunio \\ Department of Civil Engineering, Quaid- \\ e-Awam University of Engineering, \\ Science \& Technology, Pakistan \\ zaheerahmedtunnio@gmail.com
}

Nawab Ali Lakho

Department of Civil Engineering, Quaide-Awam University of Engineering, Science \& Technology, Pakistan nawablakho@gmail.com

\author{
Bashir Ahmed Memon \\ Department of Civil Engineering, Quaid- \\ e-Awam University of Engineering, \\ Science \& Technology, Pakistan \\ basher_m@hotmail.com
}

Mehboob Oad

Department of Civil Engineering, Quaide-Awam University of Engineering, Science \& Technology, Pakistan engrmahboob04@gmail.com

\author{
Noor Ahmed Memon \\ Department of Civil Engineering, Quaid- \\ e-Awam University of Engineering, \\ Science \& Technology, Pakistan \\ nahmedmemon@gmail.com
}

\begin{abstract}
Self-weight of a structure comprises a major portion of the overall structural load which causes conservative structure design. Reduction of structures' self-weight is an active area of research today. One of the options is to use lightweight concrete and no-fines concrete is one of its types. This type of concrete is made with coarse aggregates, cement, and water. From the density point of view, it is the lighter concrete compared to normal weight concrete but it exhibits less strength. Normally nofines concrete is manufactured with uniform size aggregates. The performance of no-fines concrete depends on the cementaggregate ratio and water-cement $(w / c)$ ratio. This study focuses on investigating experimentally the effect of gradation of coarse aggregates and the w/c ratio on unit weight and compressive strength of no-fines concrete. NFC with two cement-aggregate ratios (1:6 and 1:8) having seven combinations of coarse aggregate gradations $(10-5 \mathrm{~mm}, 16-13 \mathrm{~mm}, 20-16 \mathrm{~mm}, 20-13 \mathrm{~mm}$, $20-10 \mathrm{~mm}, 16-10 \mathrm{~mm}$ and $20-5 \mathrm{~mm}$ ) were studied. Two w/c ratios are considered 0.38 and 0.42 . The effect of coarse aggregate gradation, cement-aggregate ratio and $w / c$ ratio are studied in terms of unit weight and compressive strength of NFC. The results reveal the pronounced effect of aggregate gradation on the compressive strength and unit weight of the concrete. Also, a substantial effect on the unit weight and compressive strength is observed with the variation in cement-aggregate ration and the w/c ratio.
\end{abstract}

Keywords-no-fines;aggregate graddation;cement to agggregate proportion;compressive strength;texture

\section{INTRODUCTION}

No-fines concrete is a form of light weight concrete, which is made with only cement, water and coarse aggregates. The coarse aggregates are coated with cement paste and connected point-to-point with thin cement paste which holds the aggregates in a matrix. However, it is believed that it has less Corresponding author: Z. A. Tunio strength than the ordinary concrete $[1,2]$. No-fines concrete has many advantages including its prime property of lightweight and no segregation due to its porous nature avoiding need of vibration during its manufacturing [3]. Due to its high porous nature it has many applications like permeable pavements [4], water purification plants [5], and parking for light weight vehicles. The ordinary concrete is impermeable which not only hinders the percolation of water to recharge the underground water but also causes high risks of flooding [6-8]. Thus, an increasing trend is observed to use porous concrete in environmental problems and sustainable construction. No-fines concrete is generally made with uniform and large size coarse aggregates which produce pours/voids in the concrete resulting in the lightweight capacity of the concrete but exhibiting low compressive strength and workability. However, it is reported that the gradation of coarse aggregates also affects the strength properties of concrete, therefore it is suggested that with controlling coarse aggregate gradation strength can be increased [9]. Tthe size of aggregates also affects its properties [10]. Many attempts have been made to study the durability and corrosion [11], porosity and permeability [12] of no-fines concrete. Strength of no-fines concrete is affected with amount, quality and type of cement. The cement-aggregate ratio of nofines concrete may vary from 1:4 to 1:10. The porous state of NFC causes decrease in workability [2]. Hence w/c ratio also plays significant role in manufacturing NFC and its strength properties. This study is focused on investigating strength and unit weight properties of no-fines concrete with various coarse aggregate grades, cement-aggregate ratio and $\mathrm{w} / \mathrm{c}$ ratio.

\section{EXPERIMENTAL PROCEDURE}

The main aim of this study is to investigate the unit weight and compressive strength of no-fines concrete. Two cement- 
aggregate (c-a) proportions 1:6 and 1:8 of NFC were adopted. Seven different coarse aggregate gradations $(10-5 \mathrm{~mm}, 16-$ $13 \mathrm{~mm}, 20-16 \mathrm{~mm}, 20-13 \mathrm{~mm}, 20-10 \mathrm{~mm}, 16-10 \mathrm{~mm}$ and $20-$ $5 \mathrm{~mm}$ ) were used. NFC is cast with 0.38 and $0.42 \mathrm{w} / \mathrm{c}$ ratio to check its effect on the NFC behaviour. Ordinary Portland cement (OPC) as per standard of ASTM C150 was used to manufacture the NFC. Crushed stones obtained from the local market were used as coarse aggregates. They were washed and air dried up to SSD followed by accordingly sieving to achieve specified aggregate gradation. Water acceptable for drinking was used for specimen casting and curing. A total number of 140 cube specimens of $150 \mathrm{~mm} \times 150 \mathrm{~mm} \times 150 \mathrm{~mm}$ were cast. Table I gives the details of the cast and tested specimens.

TABLE I. SPECIMEN DETAILS

\begin{tabular}{|c|c|c|c|c|}
\hline S.No & $\begin{array}{c}\text { Aggregate gradation } \\
\text { (cement-aggregate) } \\
(\mathbf{m m})\end{array}$ & $\begin{array}{c}\text { Cement- } \\
\text { aggregate (c-a) } \\
\text { proportion }\end{array}$ & w/c ratio & $\begin{array}{l}\text { Number of } \\
\text { specimens }\end{array}$ \\
\hline \multirow{4}{*}{1} & \multirow{4}{*}{$(10-5)$} & \multirow{2}{*}{$1: 6$} & 0.38 & 5 \\
\hline & & & 0.42 & 5 \\
\hline & & & 0.38 & 5 \\
\hline & & $1: 8$ & 0.42 & 5 \\
\hline \multirow{4}{*}{2} & \multirow{4}{*}{$(16-13)$} & \multirow{2}{*}{$1: 6$} & 0.38 & 5 \\
\hline & & & 0.42 & 5 \\
\hline & & \multirow{2}{*}{$1: 8$} & 0.38 & 5 \\
\hline & & & 0.42 & 5 \\
\hline \multirow{4}{*}{3} & \multirow{4}{*}{$(20-16)$} & \multirow{2}{*}{$1: 6$} & 0.38 & 5 \\
\hline & & & 0.42 & 5 \\
\hline & & \multirow{2}{*}{$1: 8$} & 0.38 & 5 \\
\hline & & & 0.42 & 5 \\
\hline \multirow{4}{*}{4} & \multirow{4}{*}{$(20-13)$} & \multirow{2}{*}{$1: 6$} & 0.38 & 5 \\
\hline & & & 0.42 & 5 \\
\hline & & \multirow{2}{*}{$1: 8$} & 0.38 & 5 \\
\hline & & & 0.42 & 5 \\
\hline \multirow{4}{*}{5} & \multirow{4}{*}{$(20-10)$} & \multirow{2}{*}{$1: 6$} & 0.38 & 5 \\
\hline & & & 0.42 & 5 \\
\hline & & \multirow{2}{*}{$1: 8$} & 0.38 & 5 \\
\hline & & & 0.42 & 5 \\
\hline \multirow{4}{*}{6} & \multirow{4}{*}{$(16-10)$} & \multirow{2}{*}{$1: 6$} & 0.38 & 5 \\
\hline & & & 0.42 & 5 \\
\hline & & \multirow{2}{*}{$1: 8$} & 0.38 & 5 \\
\hline & & & 0.42 & 5 \\
\hline \multirow{4}{*}{7} & \multirow{4}{*}{$(20-5)$} & \multirow{2}{*}{$1: 6$} & 0.38 & 5 \\
\hline & & & 0.42 & 5 \\
\hline & & \multirow{2}{*}{$1: 8$} & 0.38 & 5 \\
\hline & & & 0.42 & 5 \\
\hline
\end{tabular}

All the ingredients of the respective mixes were batched accordingly in an electric operated mixer and casting of specimens was done accordingly. The specimens were demoulded after 24 hours of casting and kept in curing tank up to the age of testing. Wet curing was applied. All specimens were tested at 28 days of age. Before testing the specimens for compressive strength, all the specimens were weighed to determine their unit weight. To determine compressive strength, the cubes were tested in a universal testing machine (UTM). The cubes were placed with the cast faces in contact with platens of the testing. Then, compressive load was applied gradually. The ultimate load at the crushing failure of cube specimens was recorded. The load divided by the cross sectional area of the cube determines the ultimate compressive strength. Five cube specimens of each mix were cast from each batch. The ultimate compressive strength and unit weight of each of the five specimens was measured. The average of the five values represents the ultimate compressive strength and unit weight of the respective batch of no-fines concrete.

\section{RESULTS AND DISCUSSION}

\section{A. Compressive Strength}

The results of average compressive strength tests are presented in Table II.

TABLE II. AVERAGE COMPRESSIVE STRENGTH AND UNIT WEIGHT

\begin{tabular}{|c|c|c|c|c|c|}
\hline S.No. & $\begin{array}{c}\text { Aggregate } \\
\text { gradation } \\
(\mathbf{m m})\end{array}$ & $\begin{array}{c}\text { Cement- } \\
\text { aggregate (c-a) } \\
\text { proportion }\end{array}$ & $\begin{array}{l}\text { w/c } \\
\text { ratio }\end{array}$ & $\begin{array}{l}\text { Comp } \\
\text { (MPa) }\end{array}$ & $\begin{array}{c}\text { Unit } \\
\text { weight }(\mathrm{kg} / \mathrm{m3})\end{array}$ \\
\hline \multirow{4}{*}{1} & \multirow{4}{*}{$(10-5)$} & \multirow{2}{*}{$1: 6$} & 0.38 & 9.2 & 1889 \\
\hline & & & 0.42 & 12.4 & 1965 \\
\hline & & \multirow{2}{*}{$1: 8$} & 0.38 & 7.1 & 1944 \\
\hline & & & 0.42 & 6.1 & 1835 \\
\hline \multirow{4}{*}{2} & \multirow{4}{*}{$(16-13)$} & \multirow{2}{*}{$1: 6$} & 0.38 & 4.7 & 1759 \\
\hline & & & 0.42 & 7.1 & 1717 \\
\hline & & \multirow{2}{*}{$1: 8$} & 0.38 & 3.6 & 1734 \\
\hline & & & 0.42 & 5.9 & 1769 \\
\hline \multirow{4}{*}{3} & \multirow{4}{*}{$(20-16)$} & \multirow{2}{*}{$1: 6$} & 0.38 & 8.7 & 1878 \\
\hline & & & 0.42 & 10.7 & 1778 \\
\hline & & \multirow{2}{*}{$1: 8$} & 0.38 & 6.8 & 1789 \\
\hline & & & 0.42 & 6.5 & 1717 \\
\hline \multirow{4}{*}{4} & \multirow{4}{*}{$(20-13)$} & \multirow{2}{*}{$1: 6$} & 0.38 & 8.9 & 1839 \\
\hline & & & 0.42 & 12.1 & 1840 \\
\hline & & \multirow{2}{*}{$1: 8$} & 0.38 & 7.9 & 1860 \\
\hline & & & 0.42 & 10.5 & 1924 \\
\hline \multirow{4}{*}{5} & \multirow{4}{*}{$(20-10)$} & \multirow{2}{*}{$1: 6$} & 0.38 & 11.2 & 1906 \\
\hline & & & 0.42 & 15.7 & 1881 \\
\hline & & \multirow{2}{*}{$1: 8$} & 0.38 & 8.8 & 1807 \\
\hline & & & 0.42 & 12.4 & 1859 \\
\hline \multirow{4}{*}{6} & \multirow{4}{*}{$(16-10)$} & \multirow{2}{*}{$1: 6$} & 0.38 & 9.6 & 1929 \\
\hline & & & 0.42 & 10.7 & 1846 \\
\hline & & \multirow{2}{*}{$1: 8$} & 0.38 & 6.5 & 1807 \\
\hline & & & 0.42 & 8.4 & 1833 \\
\hline \multirow{4}{*}{7} & \multirow{4}{*}{$(20-5)$} & \multirow{2}{*}{$1: 6$} & 0.38 & 9.7 & 1902 \\
\hline & & & 0.42 & 12 & 1924 \\
\hline & & \multirow{2}{*}{$1: 8$} & 0.38 & 7.9 & 1818 \\
\hline & & & 0.42 & 7.5 & 1834 \\
\hline
\end{tabular}

Figures 1 and 2 compare the effects of aggregate gradation and cement-aggregate (c-a) proportion on the compressive strength of no fines concrete.

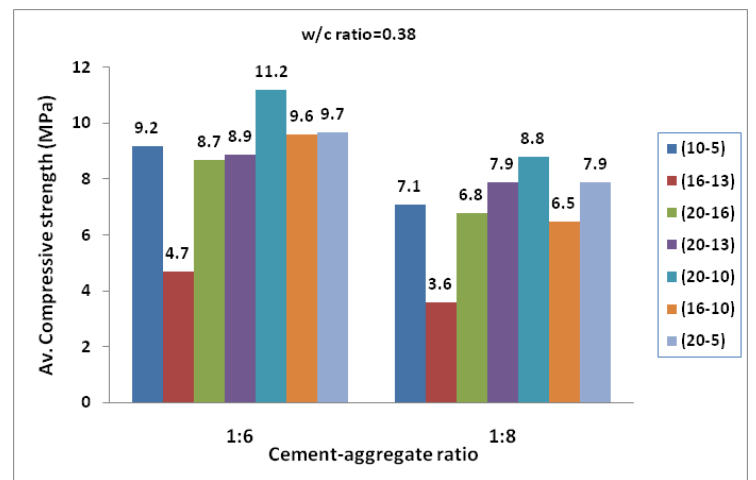

Fig. 1. Compressive strength $\mathrm{v} / \mathrm{s}$ aggregate gradation and cementaggregate proportion at $0.38 \mathrm{w} / \mathrm{c}$ ratio.

The results reveal the pronounced effects of aggregate gradation and the c-a proportion on the compressive strength. 
Figures 3 and 4 depict the effect of w/c ratio on the compressive strength of NFC. The significant effect of aggregate gradation is self-evident from the Table values and the Figures.

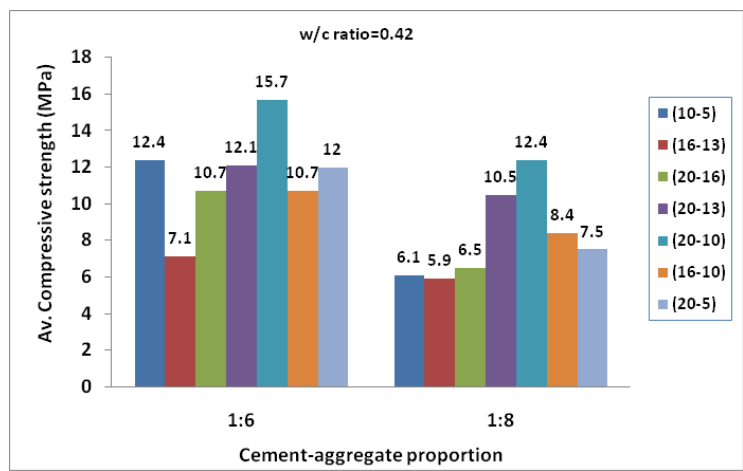

Fig. 2. Compressive strength $\mathrm{v} / \mathrm{s}$ aggregate gradation and cementaggregate proportion at $0.38 \mathrm{w} / \mathrm{c}$ ratio.

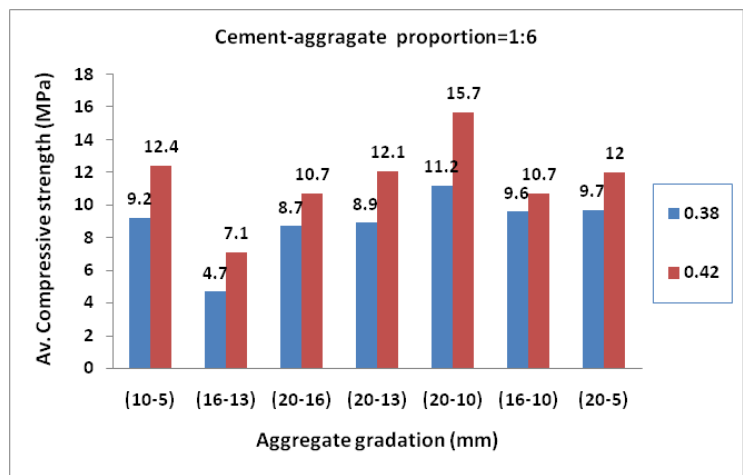

Fig. 3. Compressive strength v/s water-cement of NFC with 1:6 cementaggregate proportion

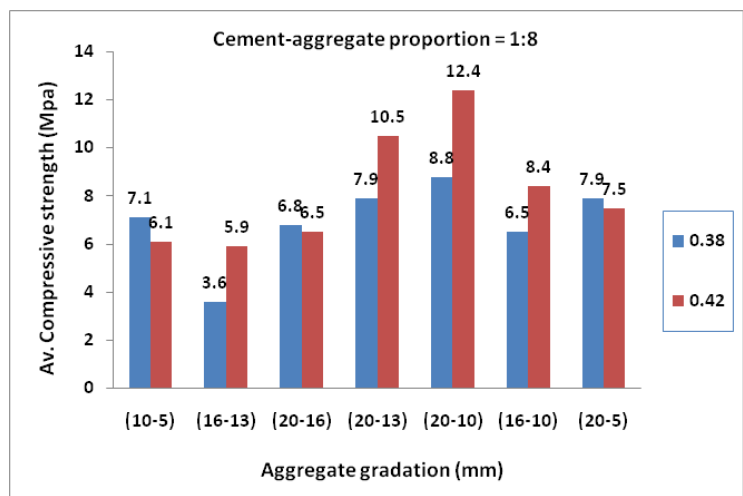

Fig. 4. Compressive strength v/s water-cement of NFC with 1:8 cementaggregate proportion

NFC manufactured with (20-10)mm gradation exhibited the highest and NFC with (16-13)mm gradation yielded the lowest compressive strength in the respective group of NFC having the same c-a proportion and w/c ratio. The compressive strength of NFC with 1:6 c-a proportion exhibited higher compressive strength than the NFC with 1:8 c-a proportion with the same aggregate gradation and w/c ratio. The NFC produced with $0.42 \mathrm{w} / \mathrm{c}$ ratio yielded higher compressive strength than that of NFC with $0.38 \mathrm{w} / \mathrm{c}$ ratio when compared to the respective batches of NFC with aggregate gradation and $\mathrm{c}-\mathrm{a}$ proportion. Minimum compressive strength of NFC is found to be $3.6 \mathrm{MPa}$ manufactured with (16-13) $\mathrm{mm}$ gradation, $1: 8 \mathrm{c}$-a proportion and $0.38 \mathrm{w} / \mathrm{c}$ ratio while the maximum value of the same mix was 7.1MPa with 1:6 c-a proportion and 0.42 $\mathrm{w} / \mathrm{c}$ ratio. The same trend is observed in case of NFC having (20-10) $\mathrm{mm}$ aggregate gradation being $8.8 \mathrm{MPa}$ with $1: 8 \mathrm{c}-\mathrm{a}$ proportion and $0.38 \mathrm{w} / \mathrm{c}$ ratio, increased to $11.2 \mathrm{MPa}(1: 6$, $0.38), 12.4 \mathrm{MPa}(1: 8,0.42)$ and $15.7 \mathrm{MPa}(1: 6,0.42)$. Difference in compressive strength of the order of $336 \%$ is observed when highest compressive strength $15.7 \mathrm{MPa}$ of NFC having (20-10) $\mathrm{mm}$ aggregate gradation, 1:6 $\mathrm{c}$-a proportion and $0.42 \mathrm{w} / \mathrm{c}$ ratio is compared to the lowest value of $3.6 \mathrm{MPa}$ of NFC having (1613) $\mathrm{mm}$ aggregate gradation, $1: 6 \mathrm{c}$-a proportion and $0.42 \mathrm{w} / \mathrm{c}$ ratio. This infers the significance of aggregate gradation, cement-aggregate proportion and w/c ratio on the compressive strength of NFC.

\section{B. Unit Weight}

Table II also shows the values of average unit weight of NFC produced with different aggregate gradation, cement aggregate proportion and $\mathrm{w} / \mathrm{c}$ ratio. The maximum unit weight of NFC observed is $1965 \mathrm{~kg} / \mathrm{m}^{3}$ and the minimum was found to be $1717 \mathrm{~kg} / \mathrm{m}^{3}$. The difference between maximum and minimum values is only $14.4 \%$. The unit weight of NFC is affected by variations in aggregate gradation, $\mathrm{c}$-a proportion and w/c ratio but it is not only marginal but also without any trend in terms of the gradation range, value of $\mathrm{c}-\mathrm{a}$ proportion and w/c ratio (Figure 5). The effect of aggregate gradation, $c-a$ proportion and w/c ratio may be considered as marginal if the unit weight is the major parameter of consideration while producing NFC otherwise their effect may be ignored.

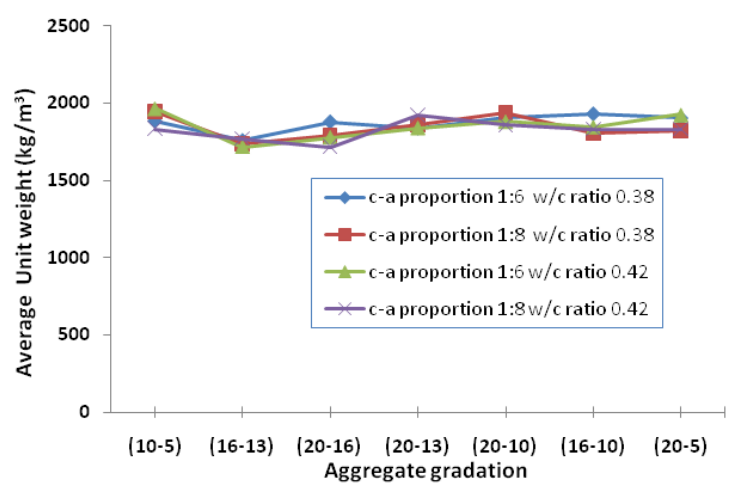

Fig. 5. Unit weight of NFC with different aggregate gradation, c-a proportion and $\mathrm{w} / \mathrm{c}$ ratio

\section{Texture of NFC}

In addition to compressive strength and unit weight, the apparent texture of the NFC is also observed in terms of variation in aggregate gradation. Figure 6 depicts texture pictorial comparison. As expected, NFC produced with aggregate gradation owing wider range of gradation and small size aggregates (e.g. $10-5 \mathrm{~mm}$ and $20-5 \mathrm{~mm}$ ) results in apparently dense and good looking texture with small voids as compared to the NFC having close range gradation and larger 
size aggregates (e.g. 16-13mm and 20-10mm). However, in case of no fines concrete, this factor may not be considered as important as it is compressive strength and unit weight.

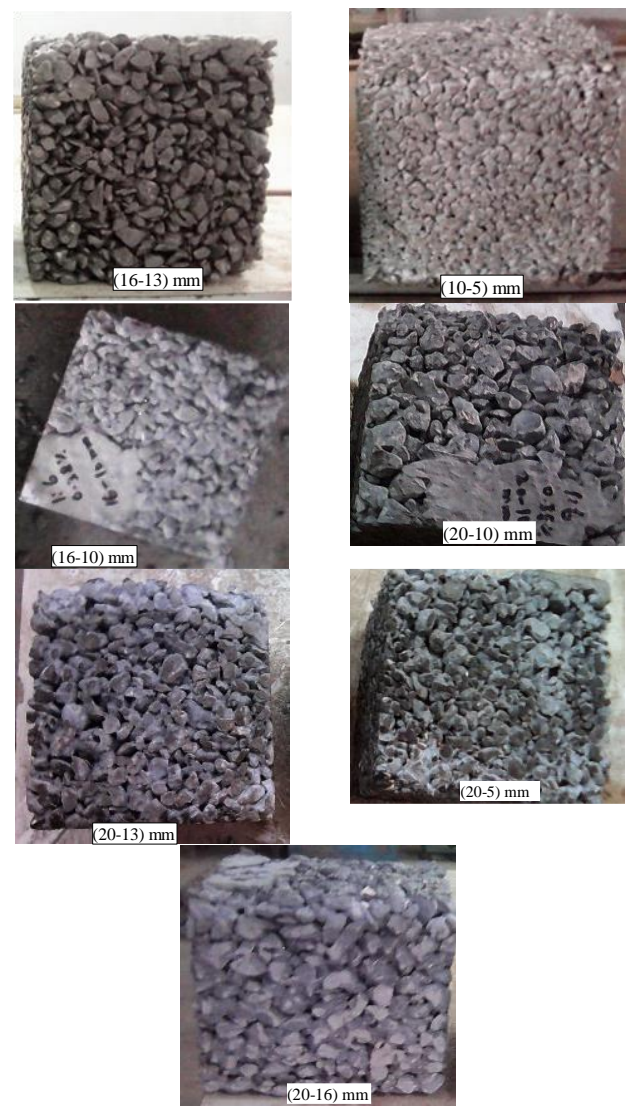

Fig. 6. Pictorial views of the texture of NFC

\section{CONCLUSIONS}

- Aggregate gradation, cement-aggregate proportion and w/c ratio significantly affect the compressive strength of no fines concrete.

- A difference as high as $336 \%$ is observed between maximum and minimum compressive strength of no-fines concrete due to variation in aggregate gradation, c-a proportion and $\mathrm{w} / \mathrm{c}$ ratio.

- No-fines concrete produced with (20-10) mm gradation, 1:6 $\mathrm{c}-\mathrm{a}$ proportion and $0.42 \mathrm{w} / \mathrm{c}$ ratio exhibited the highest compressive strength of $15.7 \mathrm{MPa}$.

- Minimum compressive strength was found to be $3.6 \mathrm{MPa}$ in the case of (16-17) $\mathrm{mm}$ aggregate gradation, 1:8 c-a proportion and 0.38 ratio.

- The unit weight of no-fines concrete is found to be marginally affected by the variation in aggregate gradation, $\mathrm{c}$-a proportion and $\mathrm{w} / \mathrm{c}$ ratio.

- The maximum difference between the minimum and maximum unit weight is found to be only about $14 \%$.
- Apparent texture of the no fines concrete was also influenced by the aggregate gradation. No fines concrete with wide rage gradation and smaller size aggregates exhibited apparently good looking and dense texture.

Based on the results of the conducted experimental study and the discussion and conclusions made above it may be concluded that while producing no fines concrete, gradation of aggregates, c-a ratio and w/c ratio may be chosen appropriately, particularly when the compressive strength is the major parameter of consideration. However, to a limited extent, unit weight and apparent texture also depend upon these factors.

\section{ACKNOWLEDGMENT}

Authors are grateful to the Quaid-e-Awam University of Engineering, Science and Technology, Nawabshah for providing the research facilities.

\section{REFERENCES}

[1] M. A. Memon, M. A. Bhutto, N. A. Lakho, I. A. Halepoto, A. N Memon, "Effects of Uncrushed Aggregate on the Mechanical Properties of No-Fines Concrete", Engineering, Technology \& Applied Science Research, Vol. 8, No. 3, pp. 2882-2886, 2018

[2] K. B. Thombre, A. B. More, S. R. Bhagat, "Investigation of Strength and Workability in No-Fines Concrete", International Journal of Engineering Research \& Technology, Vol. 5, No. 9, pp. 390-393, 2016

[3] T. Kuennen, "A New Era for Permeable Pavements. Better Roads for the Government/Contractor Project Team", Better Roads Magazine, Vol. 2003, No. 4, pp. 28-32, 2003

[4] V. R. Schaefer, K. Wang, M. T. Suleiman, J. T. Kevern, Mix Design Development for Pervious Concrete in Cold Weather Climates, Final Report, Center for Transportation Research and Education, Iowa State University, 2006

[5] J. T. Kevern, "Advancement of pervious concrete technology", $\mathrm{PhD}$ Thesis, Iowa State University, USA, 2008

[6] A. V. Novo, J. R. Bayon, D. Castro-Fresno, J. Rodriguez-Hernandez, "Temperature Performance of Different Pervious Pavements: Rainwater Harvesting for Energy Recovery Purposes", Water Resources Management, Vol. 7, No. 15, pp. 5003-5016, 2013

[7] M. J. Lee, M. G. Lee, Y. Huang, C. L. Chiang, "Purification Study of Pervious Concrete Pavement', International Journal of Engineering and Technology, Vol. 5, No. 5, pp. 532-535, 2013

[8] A. K. Jain, J. S. Chouhan, "Effect of shape of aggregate on compressive strength and permeability properties of pervious concrete", International Journal of Advanced Engineering Research and Studies, Vol. 1, No. 1, pp. 120-126, 2011

[9] Y. Zhifeng, W. Ma, W. Shen, M. Zhou, "The aggregate gradation for the porous concrete perviousroad base material", Journal of Wuhan University of Technology-Matererials Science Edition,Vol. 23, No. 3, pp. 391-394, 2008

[10] L. K. Crouch, P. E., J. Pitt, R. Hewitt, "Aggregate Effects on Pervious Portland cement Concrete StaticModulus of Elasticity", ASCE Journal of Materials in Civil Engineering, Vol. 19, No. 7, pp. 561-568, 2007

[11] M. Carsana, F. Tittarelli, L. Bertolini, "Use of No-Fines concrete as a Building Materials: Strength, Durability Properties and Corrosion protection of embedded steel", Cement and Concrete Research, Vol. 48, pp. 64-73, 2013

[12] A. B. Kabir, K. S. Islam, "Performance study on no fines concrete", 3rd International Conference on Civil Engineering for Sustainable Development (ICCESD), KUET, Khulna, Bangladesh, February 12-14, 2016 